Original Research Article

\title{
The use of ATC/DDD WHO 2016 and prescription audit study in the dermatology OPD of a tertiary care hospital in Jharkhand, India
}

\author{
Priyanki Mishra1, Shruti Suman², Umashanker P. Keshri', \\ Pranay Kumar Mishra ${ }^{3}$ Kusum Kumari ${ }^{1 *}$
}

\begin{abstract}
${ }^{1}$ Department of Pharmacology,
${ }^{2}$ Department of Venerology and Leprosy, RIMS, Ranchi, Jharkhand, India

${ }^{3}$ Department of Surgery, Tinplate Hospital, Jamshedpur, Jharkhand, India
\end{abstract}

Received: 29 September 2018

Accepted: 26 October 2018

\section{*Correspondence to:}

Dr. Kusum Kumari,

Email: research.jra@gmail.com

Copyright: (C) the author(s), publisher and licensee Medip Academy. This is an openaccess article distributed under the terms of the Creative Commons Attribution NonCommercial License, which permits unrestricted noncommercial use, distribution, and reproduction in any medium, provided the original work is properly cited.

\begin{abstract}
Background: To study the prescribing patterns, rationale of drug usage and use of anatomical, therapeutic, chemical (ATC) and defined daily dosage (DDD) classification for the monitoring of drug utilization in the dermatology department of a tertiary care hospital.

Methods: A retrospective, observational study was conducted in out-patients department of dermatology at RIMS, Ranchi over a period of two months. Rationale of drug usage was assessed by analysing the prescriptions. Defined daily dosage/1000 patients/day of the commonly used medications was compared to the defined daily dosage by World Health Organization in 2016. Data was analysed by statistical tools. Most of the results were expressed in percentages.

Results: The prescriptions were rational in most of the cases. Emphasis was more towards the branded drugs. Polypharmacy was evident in many of the prescriptions. The number of DDD/1000 patients/day in cases of antifungals was more than the WHO DDD and less than the WHO DDD in case of antihistaminics.

Conclusions: The number of drugs per prescription must be rationalized so as to avoid polypharmacy. The drugs should be prescribed by their generic names also along with the brand names. Generic medicines should be available in the hospital pharmacy so that a more cost-effective treatment can be assured. CMEs and stewardship programs for health care professionals regarding rational drug usage should be organized.
\end{abstract}

Keywords: ATC/DDD, Drug usage, Dermatology, Prescription, Rationale

\section{INTRODUCTION}

The diseases exclusively affecting the superficial layers of the skin are referred to as skin diseases. ${ }^{1}$ With prevalence rate of $10 \%$, population affected across India from skin diseases is nearly 15.1 crore. $^{2}$ Dermatological pathogens are responsible for upto $2 \%$ of the consultations in general practice all over the world. ${ }^{3}$

The common skin disorders in developing countries have not been regarded as a significant problem that need important public health measures. Little recent literature is available on skin diseases. The incidence data in the general population is very limited and have a considerable difference from one place to another. ${ }^{4}$

Periodic audit of prescriptions is essential to improve drug utilization patterns and restrict irrational prescribing. ${ }^{5}$ It also helps to achieve cost-effective medical care and provides an insight into the quality of health care at that centre. Polypharmacy, drug interactions and adverse reactions that can occur can be derived from the proper analysis of prescriptions. The prescription reflects the 
physician's attitude towards the disease and the role of the drug prescribed by him. ${ }^{6}$

Drug utilization studies are required to identify the trends as well as to set the priorities, not only in the interest of the regulatory control, but also as a basis of the planning program of education and information. ${ }^{7}$ Previous studies on promotion of evidence based medicine in Australia conclude that academic detailing led to a significant improvement perceived understanding of the practitioners and the quality of the prescriptions. ${ }^{8}$

In 1969, a symposium entitled "The Consumption of Drugs" took place in Oslo by the WHO regional office for Europe. Here, The Drug Utilization Research Group was tasked with the development of internationally applicable methods for drug utilization research. Thus, the ATC/DDD system was born in Norway in the early seventies. It was globalized in 1996 by WHO. The members of the working group are Australia, Japan, India, Pakistan, Morocco, Ghana, Zimbabwe, USA, Australia, The Netherlands and Sweden.

Indian studies have used the ATC/DDD concept in various drug utilization studies for brief periods. ${ }^{9}$

Irrational prescriptions lead to significant wastage of money and resources in developing countries and ultimately to poor patient outcome. So, authors undertook this study in accordance with the ATC/DDD methodology to determine the prevalence of prescribing pattern by calculating DDD/1000 patients/day for the commonly prescribed drugs that find a place in the ATC classification 2016 by WHO. An attempt was also made to relate the data with two demographic characteristics, viz, age and sex to develop patient population data base.

\section{METHODS}

A total of 650 prescriptions were collected from the OPD of the Skin and Veneral Diseases Department of Rajendra Institute of Medical Sciences, Ranchi from the $1^{\text {st }}$ of November to the $30^{\text {th }}$ of December 2017.

A retrospective, institution based cross-sectional study was conducted. The samples were collected by systematic random sampling.

The study population consisted of all patients who visited the department of Dermatology, RIMS and for whom medicines were prescribed during the study period, irrespective of their age and sex or the disease in question.

Twenty prescriptions were excluded from the study as they were either follow up prescriptions or had only investigational advice.

First of all, the data was demographically classified according to the age group and sex of the patient. Then, it was analyzed according to the WHO core indicators on drug use. The percentage distribution according to the therapeutic classification of the drugs was ascertained. The fixed dose products were counted as a single product as per the WHO norms. The percentage of drugs according to the national list of essential medicines was calculated.

The ATC/DDD of important drugs were looked into and the number of DDD/1000 patient/day was calculated. The DDD/1000patient/day=Total number of dosage strengths of unit prescribed*each dosage*1000/DDD*duration of study* sample size. ${ }^{9}$

Percentage cost of various drug classes were calculated. The average total cost of drug per prescription in the pharmacy and in the generic drug store was calculated in INR and was compared.

\section{Statistical analysis}

Number and percentages were used to express the result. Libre Office Calc was used for the statistical calculations. $\mathrm{P}$ was set at 0.05 .

\section{RESULTS}

A total of 630 prescriptions were analysed. Out of these, $78.57 \%$ (495) were male. Females comprised of $21.43 \%$ (135) of the study group.

Irrespective of the sex, the age group of 20-60 had the maximum number of patients i.e. $71.42 \%$. $26.99 \%$ prescriptions belonged to the age group less than 20 whereas only $1.58 \%$ of the sample size was above 60 years (Table 1).

Table 1: Percentage of sex and age groups.

\begin{tabular}{|lll|}
\hline Sex & Number & Percentage $(\%)$ \\
\hline Male & 495 & $79 \%$ \\
\hline Female & 135 & $21 \%$ \\
\hline Age group (years) & \\
\hline$<=20$ years & 170 & $27 \%$ \\
\hline 20 - 60 years & 450 & $71 \%$ \\
\hline$>60$ years & 10 & $2 \%$ \\
\hline
\end{tabular}

The total number of drugs prescribed was 2255. The average number of drugs per prescription was 3.6. Total number of drugs according to the National List of Essential Medicines were 1095 (48\%). 2245 (99.6\%) drugs were prescribed by brand names.

Only $10(0.44 \%)$ drugs were prescribed by generic names. The dosage form was not mentioned in 24 (1.0\%) prescriptions and the duration of the drug treatment was missing in $16(0.7 \%)$ prescriptions. The route of administration was not written in 2 prescriptions. Percentage of fixed dose combinations were $12 \%$. This analysis uses the WHO core indicators for assessing the drug prescriptions (Table 2). 
Table 2: WHO core indicators assessing drug prescription.

\begin{tabular}{|ll|}
\hline Indicators & Percentage \\
\hline Total number of drugs prescribed & 2255 \\
\hline $\begin{array}{l}\text { Average number of drugs per } \\
\text { prescription }\end{array}$ & 3.6 \\
\hline $\begin{array}{l}\text { Number of drugs according to the } \\
\text { National List of Essential Medicines }\end{array}$ & $1095(48 \%)$ \\
\hline Drugs prescribed by brand names & $2245(99.6 \%)$ \\
\hline Drugs prescribed by generic names & $10(0.44 \%)$ \\
\hline Dosage form not mentioned & $24(1.0 \%)$ \\
\hline $\begin{array}{l}\text { Duration of the drug treatment } \\
\text { missing }\end{array}$ & $16(0.7 \%)$ \\
\hline Route of administration not written & $2(0.088 \%)$ \\
\hline $\begin{array}{l}\text { Percentage of fixed dose } \\
\text { combinations }\end{array}$ & $271(12 \%)$ \\
\hline
\end{tabular}

The oral route was advised in $1330(59 \%)$ and topical route of administration was advised for 925(41\%) drugs. Not a single drug was advised via any parenteral route (Figure 1).

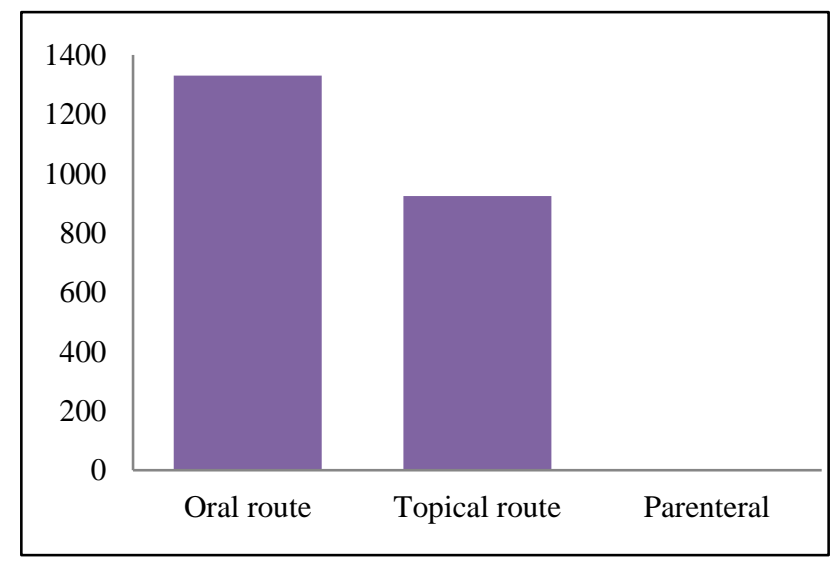

Figure 1: Routes of drug administration.

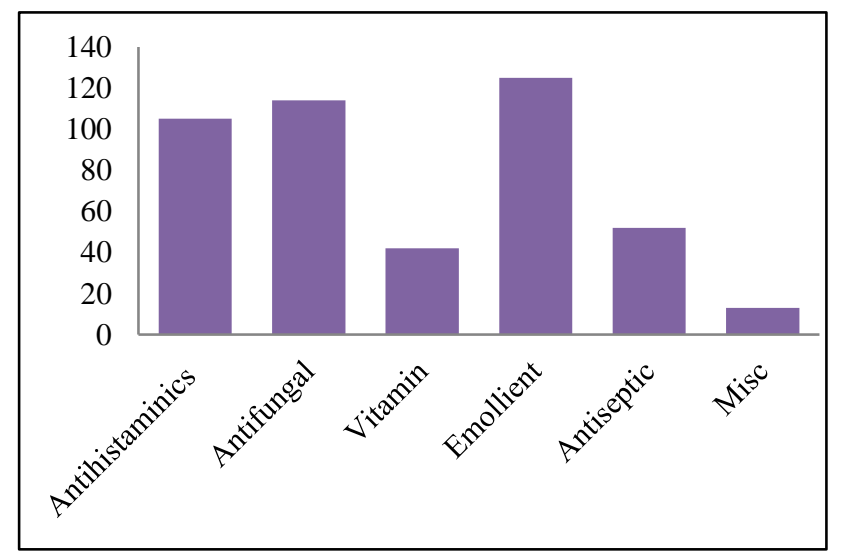

Figure 2. Percentage distribution of various drug groups.

The emollients were the most prescribed $(27.71 \%)$. And contained topical preparations of antifungals along with corticosteroids and astringents mainly. The antifungals were frequently prescribed drugs (25.27\%), closely followed by antihistaminics $(23.28 \%)$. The antiseptic group was the next $(11.53 \%)$ and the vitamins were also given commonly $(9.31 \%)$. The miscellaneous group comprised of shampoos, sunscreens etc $(2.89 \%)$. The corticosteroids were not prescribed orally or parenterally, only being present in the topical preparations as combination therapy. No antibiotics were prescribed (Figure 2).

The average cost of antifungals is $37 \%$, followed by emollients i.e. $27 \%$. Vitamins cost $21 \%$, antiseptics $8 \%$ and antihistaminics $5.7 \%$ of the total cost on an average. The miscellaneous group comprises of $1 \%$ of the total average cost (Figure 3).

The average total cost of the drugs per prescription is 878.25 INR if the branded medicines are used. If the generic drugs are used, 283 INR is the average total cost. There is a significant amount of difference in the two costs which is similar to other studies. ${ }^{4}$

The number of DDD/1000 patients/day of itraconazole in the dosage of $100 \mathrm{mg}$ twice daily is 0.8 . If the dose is $200 \mathrm{mg}$ twice daily, then it is 1.5 . For terbinafine $250 \mathrm{mg}$ twice daily for 28 days, it is 0.7 and for $500 \mathrm{mg}$ twice daily, it is 1.5 . For levocetrizine $100 \mathrm{mg}$ daily for 30 days, it is 0.02 (Table $3)$.

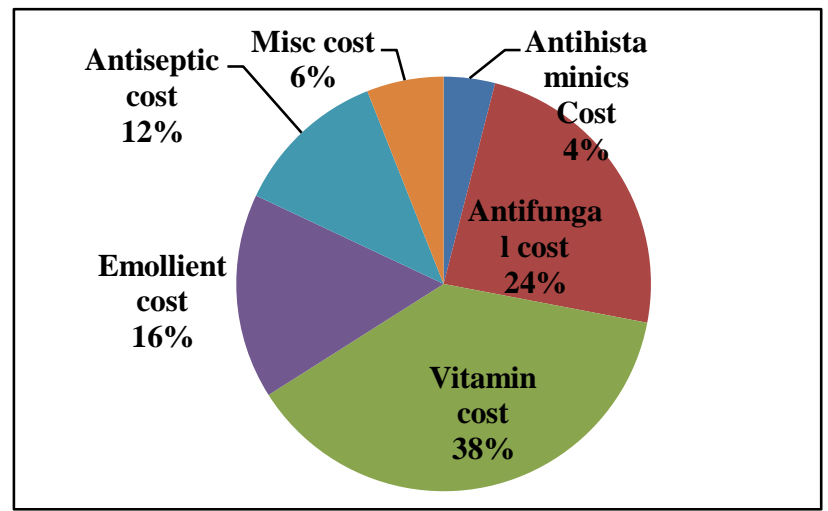

Figure 3: Percentage cost of various drug classes.

Table 3: ATC Code and DDD/1000 patients/day.

\begin{tabular}{|llll|}
\hline Drug name & $\begin{array}{c}\text { ATC } \\
\text { code of } \\
\text { the drug }\end{array}$ & $\begin{array}{c}\text { WHO } \\
\text { DDD }\end{array}$ & $\begin{array}{c}\text { DDD/1000 } \\
\text { patients /day }\end{array}$ \\
\hline Itraconazole & J02AC02 & 0.2 & $\frac{(100 \mathrm{mg}) \mathrm{bd}=0.8}{(200 \mathrm{mg}) \mathrm{bd}=1.5}$ \\
\hline Terbinafine & D01B0A2 & 0.25 & $\frac{(250 \mathrm{mg}) \mathrm{bd}=0.7}{(500 \mathrm{mg}) \mathrm{bd}=1.5}$ \\
\hline Levocetrizine & R06AE09 & 5 & $(100 \mathrm{mg}) \mathrm{od}=5$ \\
\hline
\end{tabular}

\section{DISCUSSION}

Though there are several studies related to the prescribing pattern in the dermatology OPD, data is lacking for studies 
in the Chhotanagpur plateau region (Jharkhand) of India. Present study target was to know the pattern of drug usage for the skin ailments in this area. Hence, this study was done to know and verify the utilization pattern of drugs in the Dermatology OPD of a tertiary care teaching hospital of this region.

Knowing the trends of skin disorders is necessary for rational prescribing and appropriate management. ${ }^{3}$ In present study, authors found all varieties of tinea infections as the most common pathology, followed by pityriasis and scabies. This result may be attributed to the factors like humidity of this region, poor hygiene of the low socioeconomic population visiting the OPD and overcrowding. These findings highlight the morbidity pattern of this region.

The mean number of drugs per prescription was 3.6. It is high in comparison to other studies where it is 2.4 and 2.7 respectively. ${ }^{1}$ Keeping the number of drugs to the minimum per prescription leads to lesser number of drug interactions, adverse effects and low economic burden on the patient, leading to better compliance and more successful treatment.

The high percentage of branded drugs in comparison to generic medicines is in accordance with the previous studies done in the past. ${ }^{6}$ In present study, $0.44 \%$ drugs were prescribed by their generic name. This is a dismal figure in comparison to that reported in the study conducted in western Nepal and in Delhi, where this parameter was $13 \%$ and $6.98 \%$ respectively. ${ }^{10}$ It may be a pointer to the dangerously rising promotional strategies by the pharmaceutical companies. ${ }^{11}$ This may also indicate the lack of faith of the health care professionals in the quality of generic drugs.

According to present study, males presented with the skin afflictions more than the females. Male preponderance has also been seen in a study done in a different hospital. ${ }^{12}$ The minimum number of patients from the geriatric age group may be due to their inability to reach the OPD facility due to physical inabilities, difficulty in bringing them to the OPD or sheer neglect of the family members. ${ }^{4}$ Same may be the case with the female population owing to their lesser numbers. It may also be a pointer to their better hygiene profiles in comparison to male population.

Since the drugs have been prescribed in the OPD, injectables must have been deliberately avoided to gain better patient compliance. For the same reason, oral corticosteroids must have also been avoided due to the cumbersome adjustment of dosage in these cases and a number of serious adverse reactions. Minimum use of injections is preferred, and this reduces the risk of infection through parenteral route and cost incurred in therapy.

Dosage, duration of treatment and routes of administration have been found missing in a very insignificant number of prescriptions. Also, very few fixed dose combinations have been prescribed. These signify a positive view of the drug utilization study that we have undertaken. Other studies also are of the same view point. ${ }^{11}$

In the topical preparations, the adequate dosage to be used at a time has not been mentioned. The fingertip unit must be brought more to use to avoid both subtherapeutic and toxic dose levels, both of which may be harmful to the patient. $^{13}$

The maximum percentage cost of drugs is for antifungals and the miscellaneous groups is only $1 \%$ of the total economic burden. The high use of emollients has a steroid sparing effect and hence reduces toxicity 3 This finding is in accordance with the disease pattern of the area and is highly indicative of rational prescribing.

The DDD/1000 patients/day shows the trends of prescribing of the antifungals and antihistaminics in comparison to the WHO norms for the DDD. The marked variability in use of drugs is under investigation. The comparison with prescribed daily dosage is also being evaluated. ${ }^{14}$

The study could have been more conclusive by extending the period of the study. Measurement of the socioeconomic classes, patient care indicators and associated adverse reactions could have added more meaning to this study. Addition of both direct and indirect costs would have been more appropriate. ${ }^{15}$

Rational prescribing by avoiding polypharmacy and increasing use of more drugs present in the NLEM by generic names, health care professionals can go a long way in improving the drug utilization landscape. Patient can benefit both in terms of treatment profile and cost effectiveness. These drugs should be made available in the hospital pharmacy and patients' trust should be built to rely on the efficacy of these medicines. Regular updates by CMEs and stewardship programs for the doctors to increase their awareness about proper prescribing. More drug utilization studies at regular intervals can also be very helpful.

\section{ACKNOWLEDGEMENTS}

Authors would like to thank Mr. Bhaskar Chaudhary for his assistance with the statistics.

Funding: No funding sources Conflict of interest: None declared

Ethical approval: The study was approved by the Institutional Ethics Committee

\section{REFERENCES}

1. Tegegne A, Bialfew F. Prescribing Pattern for Skin Diseases in Dermatology OPD at Boru Meda Hospital. Advance Pharmaceutical J. 2017;2(5):174-8. 
2. Jaiswal MK, Chakrawarty R, Sharma S, Sachdev D, Sharma R, Ali S. Prescription audit of Corticosteroids in Dermatology OPD of a tertiary care teaching hospital of tribal region of central-south India. Int $\mathbf{J}$ Biomed Res. 2017;8(01):20-5.

3. Mirshad PV, AK AK, Fasalu RO, TK MM. Prescription audit of corticosteroid usage in the department of dermatology at a tertiary care teaching hospital. Int J Basic Clin Pharmacol. 2017 Jan 31;2(4):411-3

4. Narwane SP, Patel TC, Shetty YC, Chikhalkar SB. Drug utilization and cost analysis for common skin diseases in dermatology OPD of an Indian tertiary care hospital-A prescription survey. Br J Pharmaceut Res. 2011 Jan 1;1(1):9.

5. Pendhari SR, Chaudhari DR, Burute SR, Bite BM. A study on the drug utilization trends in the cardiovascular emergencies in a tertiary care hospital. J Clin Diagnostic Res. 2013 Apr;7(4):666.

6. Kumar S, Dutta S, Beg MA, Mehta AK, Anjoom M, Sindhu S. Drug utilization pattern in acne vulgaris in skin outpatients department of a tertiary care teaching hospital at Dehradun, Uttarakhand. Int J Med Sci Public Health. 2014 Jul 1;3:855-8.

7. Noor N, Uddin MJ, Afsan M, Akhter H, Kabir F. Evaluation of Drug use patterns of outpatient attendees in a tertiary care teaching hospital in dermatology and venereology department as a tool to promote rational prescribing. Update Dental Coll J. 2014;4(1):4-9.

8. Hannes K, Leys M, Vermeire E, Aertgeerts B, Buntinx F, Depoorter AM. Implementing evidence-based medicine in general practice: a focus group based study. BMC family practice. 2005 Dec;6(1):37.

9. Gupta AK, Mishra S. Prescription audit study in a tertiary care hospital using the anatomical therapeutic chemical and defined daily dose classification concept. Int J Basic Clin Pharmacol. 2017 Jan 27;3(5):889-901.

10. Kumar J, Chandra S, Sinha KH. Utilization pattern of drugs among dermatological outpatients in a tertiary care hospital of eastern India IJPR. 2016;6(9):297392.

11. Deenadayalan K, Chinnam P, Kumar G. Prescription pattern of corticosteroids in dermatology cases in a tertiary care teaching hospital. J Cont Med A Dent. 2017;5(3):44-8.

12. Motgahre VM, Bajait CS, Turankar A, Pimpalkhute SA, Dholpure M. Prescription pattern and adverse drug reaction profile of drugs prescribed with focus on NSAIDs for orthopedic indications at a tertiary care hospital. Indian J Pharmacy Pharmacol. 2016;3(4):178-81.

13. Kalavala M, Mills CM, Long CC, Finlay AY. The fingertip unit: a practical guide to topical therapy in children. J Dermatol Treatment. 2007 Jan 1;18(5):31920.

14. Polk RE1, Fox C, Mahoney A, Letcavage J, MacDougall C. Measurement of adult antibacterial drug use in 130 US hospitals: comparison of defined daily dose and days of therapy. Clin Infect Dis. 2007 Mar 1;44(5):664-70.

15. Vineeta D, Sharad P, Ganachari MS, Geetanjali S, Santosh S. Assessment of drug prescribing pattern and cost analysis for skin disease in dermatological department of tertiary care hospital: an interventional study. J Pharmacovigilance. 2016 Jun 8.

Cite this article as: Mishra P, Suman S, Keshri UP, Mishra PK, Kumari K. The use of ATC/DDD WHO 2016 and prescription audit study in the dermatology OPD of a tertiary care hospital in Jharkhand, India. Int J Basic Clin Pharmacol 2018;7:2409-13. 